Arteterapia. Papeles de arteterapia y educación para inclusión social ISSN-e 1988-8309

http://dx.doi.org/10.5209/ARTE.60161

\title{
«Mirada Interior» La fotografía como herramienta de transformación social con mujeres del Centro Penitenciario de Algeciras. ${ }^{1}$
}

\author{
Alicia Conde de Vega ${ }^{2}$
}

Recibido: 8 de mayo de 2018 /Aceptado: 25 de mayo de 2018

Resumen. En este artículo se reflexiona sobre la fotografía como herramienta de transformación social. A través del trabajo realizado desde el año 2009 al 2015 en el Centro Penitenciario de Algeciras con mujeres reclusas en los talleres de fotografía bajo el título de «Mirada interior», se ha comprobado que el proceso creativo a través de la imagen permite la creación de un espacio de libertad, de encuentro con ellas mismas y con el grupo. La fotografía se convierte en una gran herramienta para trabajar aspectos importantes para su desarrollo personal y social, reflexionar sobre su identidad, mejorar su autoconcepto y su autoestima, al permitir reconocerse, aceptarse, transformarse y encontrarse ante la cámara, favoreciendo la toma de decisiones, al poder decidir tanto individual como colectivamente qué es lo que quieren y cómo mostrarlo. Así se generan nuevos procesos de comunicación a través de la interacción que facilita el acto fotográfico permitiendo, de este modo, crear relaciones intra e interpersonales más positivas convirtiendo el tiempo de condena en un tiempo educativo y socialmente útil.

Palabras clave: Prisión; fotografía; mujer; arteterapia ; transformación social.

\section{[en] «Inner Look» The photography as a tool of social transformation with women in the penitentiary of Algeciras.}

\begin{abstract}
In this article, we reflect on photography as a tool for social transformation. Through the work carried out from 2009 to 2015 in the penitentiary of Algeciras with women prisoners through photography workshops under the title of «Inner Look», it has been proven that the creative process through the image allows the creation of a space of freedom, of encounter with themselves and with the group. Photography becomes a great tool to work on important aspects for personal and social development, reflect on their identity, to get better their self-concept and self-esteem, allowing them to recognize, accept, transform and meet before the camera, favoring decision-making, to be able to decide both individually and collectively what they want and how to show it. Thus, new communication processes are generated through the interaction that facilitates the photographic act, allowing in this way, to create more positive inter and interpersonal relationships by converting the time of sentence into an educational and socially useful time.
\end{abstract}

Keywords: prision; photography; women; art therapy; social transformation.

Sumario: 1. Introducción, 2. El contexto espacio-temporal, 3. El colectivo de mujeres, 4. Objetivos taller y metodología, 5. El proceso creativo a través de la fotografía, 6 . Posibilidades de la fotografía como herramienta terapéutica y educativa en el ámbito penitenciario, 7. Conclusiones, 8. Referencias bibliográficas.

\footnotetext{
1 Subvencionado por la Delegación Territorial en Cádiz de la Consejería de Igualdad, Salud y Políticas Sociales de la Junta de Andalucía y el Instituto de la Mujer del Ministerio de Sanidad, Servicios Sociales e Igualdad.

2 Fotógrafa, arteterapeuta y educadora social condevega.alicia@gmail.com
} 
Cómo citar: Conde Vega, A. (2018). "Mirada Interior" La fotografía como herramienta de transformación social con mujeres del Centro Penitenciario de Algeciras, en Arteterapia. Papeles de arteterapia y educación para inclusión social 13, 2018, 33-52.

\section{Introducción.}

El taller de fotografía «Mirada Interion» se enmarca dentro de varios proyectos de intervención social que la Fundación Márgenes y Vínculos ${ }^{3}$ lleva a cabo en el Centro Penitenciario de Algeciras, Cádiz, desde el año 2001. El taller de fotografía se inició en el año 2009, momento en el que comienzo a trabajar en esta organización dentro del proyecto: «Integración socio familiar de mujeres reclusas y ex reclusas del Centro Penitenciario de Algeciras». El objetivo general del proyecto de intervención socioeducativa, donde se incluye el taller de fotografia, es favorecer el proceso de integración y normalización social y familiar de la población de mujeres reclusas que se encuentran en situación de riesgo o de crisis psicosocial mediante una atención integral en las áreas psicológica, social y educativa.

Dada la extensión temporal de la experiencia, se presenta desde una visión integradora del aprendizaje adquirido en estos años trabajando en el ámbito penitenciario. Utilizando el arte como herramienta de intervención social, se parte de la contextualización del espacio, que en este caso se compone de unas características especiales, que no se refiere únicamente a las estructuras físicas, sino a las consecuencias psicosociales que produce en las personas. Analizado esto, se pasa a estudiar a el colectivo de atención, compuesto por mujeres reclusas que representan una minoría dentro de las prisiones lo que produce una situación de desigualdad de trato en relación con los hombres, sin tener en cuenta como afirma Yagüe, (2007) «sus características sociales y personales que les hacen más vulnerables a la entrada en el mundo penal y el desentendimiento de sus necesidades» (p. 1), lo que repercute en su tratamiento y en la manera de «vivir» su condena. En la siguiente sección se definen los objetivos planteados y la metodología utilizada en los diversos talleres, los cuales se han ido manteniendo, a la vez que se incluyen las variaciones fruto de las evaluaciones realizadas en cada actividad, las aportaciones y necesidades detectadas y expresadas de las mujeres participantes. Esto posibilita mantener aquello que funciona, eliminar lo que no y añadir nuevas propuestas con el fin de mejorar las intervenciones. Asimismo se describe el proceso creativo a través de la imagen mediante el aprendizaje de técnicas básicas de fotografía, dinámicas de conocimiento, juego y creatividad, que permiten ir creando un espacio de confianza que facilita la reflexión, la expresión y el aprendizaje que motive al cambio. El artículo se finaliza con las conclusiones alcanzadas en relación a los beneficios y a las posibilidades de la fotografía como vía de transformación social, centrando en el ámbito penitenciario del trabajo realizado durante estos años con mujeres reclusas.

\section{El contexto espacio-temporal}

El espacio penitenciario tiene un gran peso sobre las personas que viven en él, condicionando sus actitudes, relaciones y necesidades. Un espacio de obligada permanen-

www.fmyv.org 
cia y convivencia en el que todo viene impuesto, estos es: los horarios, los espacios, las comunicaciones con el exterior, las actividades, las comidas etc. (Valverde, 1997), correspondiendo a lo que Gofmman (1961) definió como «Institución total; un lugar de residencia y trabajo, donde un gran número de individuos en igual situación, aislados de la sociedad por un periodo de tiempo apreciable, comparten en su encierro una rutina diaria» (p. 19)

Al proceso de incorporación y paulatina adaptación a este peculiar hábitat alternativo, Clemmer (1958) lo llamó "prisionización», lo que consiste en la progresiva adaptación por parte de la persona privada de libertad de una nueva forma de vida y el aprendizaje de nuevas habilidades y comportamientos. Como describe Segovia:

«La principal actividad del preso, especialmente en la etapa del ingreso, es una lucha por la supervivencia en un intento continuo de adaptarse. Puede ser más o menos acelerado, más o menos efectivo según el tiempo ininterrumpido que la persona permanezca en la cárcel, el tipo de actividades de desprisionización que desarrolle en ella, su historia de vida, personalidad y la permeabilidad que mantenga con el exterior.» (p. 5)

Este efecto de la prisionización tiene consecuencias negativas para la resocialización de las personas, efectos que hay que tener presentes en cualquier intento de atención socioeducativa y terapéutica con este colectivo, como resume Valverde (1997) en una frase «el preso no sólo vive en la prisión, sino que vive la prisión» (p. 57). Por tanto se parte de un espacio que transforma y afecta diversas áreas de la vida de las personas:

- Físicamente: tienen problemas sensoriales; en la vista, la audición, el olfato, el gusto y el tacto, produciendo un aislamiento sensorial debido a la falta de estímulos externos y agarrotamiento musculares provocados por la tensión diaria en la que se mezcla la ansiedad y una sensación continua de peligro y miedo, añadidos por la escasa movilidad con la que cuentan (Valverde, 1997).

- Psicológicamente: sufren alteraciones de la afectividad, de la sexualidad, del reconocimiento del propio cuerpo, problemas de ansiedad, pérdida de noción de la responsabilidad debido a falta de control sobre sus actividades. Esta situación conduce a un proceso de infatilización, denominado por Goffman «La mutilación del yo», que genera una pérdida de rol de adulto y un sentimiento de fuerte dependencia a la institución total (Goffman, 1961), que altera su identidad personal y social, su auto imagen y la consciencia de sí mismo.

- Socialmente: la separación forzada con la familia es una de las situaciones que más afecta a las personas presas, al estar alejados de sus seres queridos. Las mujeres sufren más esta separación en especial de sus hijos/as, casi el $80 \%$ de ellas son madres, provocando un sentimiento constante de impotencia y tristeza. Afectando a la autoestima de las mujeres, al sentir el fracaso de sus expectativas sociales marcadas por su 
condición de género, valorándose negativamente en su papel de madre y esposa (Yagüe, 2007). Incrementando su «condena moral», que produce la privación de libertad al sentirse rechazadas moral y socialmente (García-Bores, 2003).

Y como define (Valverde, 1996) sus «consistencias comportamentales» (p. 50) haciendo referencia en especial a las muchas horas de las que disponen sin hacer nada y compartiendo espacio como el patio que para las personas presas genera sensación de vacío, pérdida de control y de iniciativa. Mucho tiempo para pensar, generando ansiedad y fatalismo, lo que aumenta el riesgo de caer en la drogadicción, factores que producen un empobrecimiento vital y síndrome amotivacional (Valverde, 1997). Caracterizado por rasgos de apatía y la falta de interés para participar en cualquier actividad socioeducativa.

Otro factor importante a valorar es el tiempo, un tiempo presente que se vive lento donde cada día es igual al otro, adoptando diferentes actitudes como intentar olvidar y negar lo que viven, utilizando las drogas como vías de escape o aceptar y aprovechar el tiempo que les ha tocado vivir. El tiempo pasado, en la gran mayoría, se experimenta con sentimientos de dolor, de culpa y de arrepentimiento, enfrentándose a emociones como la ira y la tristeza por lo que han dejado fuera, en especial sus hijos/as. Ante el tiempo futuro les invade una gran incertidumbre, enfrentándose con miedo al estigma que la prisión dejará en sus vidas tanto a nivel psicológico como social.

El Centro Penitenciario de Algeciras, donde se desarrolla el taller, corresponde a las macro cárceles modernas conocidas como «cárcel tipo». Cuenta con una capacidad para 1500 personas, 1375 hombres y 125 mujeres, dispone de 15 módulos residenciales con una capacidad para 125 personas cada uno, en estos se ubican las celdas con cabida para dos personas y otros espacios de convivencia colectivos que consisten en un comedor, un patio, una sala de estar y varias aulas de formación.

Además existe un módulo sociocultural, donde se realizan diferentes actividades socioeducativas, dotado de un salón polideportivo, un gimnasio, una biblioteca, un teatro y cuatro aulas para uso de talleres. En este módulo acuden tanto hombres como mujeres, y para acceder a él tienen que estar autorizados por la Subdirección de Tratamiento que coordina todas las actividades orientadas a la formación y reinserción social de los presos/as organizadas tanto por el Centro como por las diferentes ONG que allí intervienen.

El taller de fotografía se ha realizado mayoritariamente en el módulo sociocultural, en las aulas de formación y en el teatro. Algunas sesiones se han realizado en el aula del módulo residencial de mujeres. Cada espacio cuenta con sus peculiaridades, tanto positivas como negativas a la hora de plantear un marco terapéutico. El espacio del módulo residencial, tiene como ventaja que las mujeres están más disponibles, se encuentran todas en ese espacio de convivencia, pero a la vez esa disponibilidad es más inconstante ,al tener mayores distracciones, como ir a comprar al economato, realizar llamadas de teléfono, la megafonía etc. Mientras que en el espacio sociocultural se crea una mayor concentración en la actividad, facilitando la creación del espacio terapéutico, a lo que hay que añadir la motivación de las mujeres por salir del módulo residencial. El concepto de salida aunque sea de tan sólo 100 metros de distancia, cobra un gran significado, dejar el patio que tantas tensiones produce y poder ver a otras personas e incluso el paisaje. El centro se encuentra ubicado en una zona 
de montañas a las afueras de la ciudad y la comunicación entre módulos es al aire libre lo que permite ver más cielo y naturaleza aunque sea entre muros. Lo negativo del módulo sociocultural es que existen más controles, lo que ralentiza el comienzo de la actividad. Sumado a esto la presencia de hombres que se encuentran de camino al aula o el teatro, se convierte en un elemento distractor, aunque muy comprensible por otra parte el poder saludar aunque sea desde la distancia o de manera más cercana a un familiar que también esté preso, un marido, un hijo o la pareja. Pero a la vez se convierte en un elemento de conflicto frente a algunos funcionarios de vigilancia, los cuales no ven con buena actitud esos encuentros fugaces.

\section{El colectivo de mujeres}

Las mujeres reclusas representan una minoría dentro de la población general penitenciaria según datos de Instituciones Penitenciarias de los datos estadísticos de la población reclusa femenina representan sólo el 7,39\% frente al 92,61\% de población

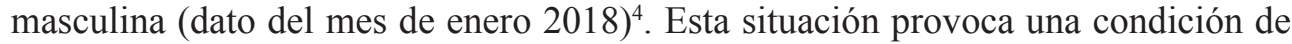
desventaja en relación a los hombres en posibilidades de acceso a oportunidades educativas y de tratamiento, produciendo una desigualdad entre ambos sexos que se traduce en menos espacios e infraestructuras adecuadas a nivel nacional para ellas, y menor atención socio educativa. Lo anterior, repercute de manera negativa en su calidad de vida dentro del centro y menos oportunidades para la reinserción en el medio libre.

El perfil de las mujeres reclusas en la actualidad ha cambiado y se presenta como muy heterogéneo, tal como afirman, Herrera y Expósito (2010) en un estudio realizado sobre las diferencias de las consecuencias de la encarcelación entre hombres y mujeres:

«La realidad de nuestras cárceles ha cambiado, si hace unas décadas lo frecuente era encontrar en ellas personas desadaptadas socialmente y que reunían las características típicas de la exclusión social, actualmente debido a los cambios sociales y legislativos, así como al endurecimiento de las penas, encontramos una población mucho más heterogénea» ( p.239).

En todos estos años han participado un total de 84 mujeres con edades comprendidas entre los 19 y 60 años. Un gran número de ellas son madres, la separación forzosa de sus hijos/as es uno de los factores que mayor ansiedad les provoca, su encarcelación afecta directamente al núcleo familiar, ellas suelen ser el soporte de la familia, tanto afectivo como económico.

Cabe destacar la presencia numerosa de mujeres extranjeras y de mujeres de etnia gitana, poniendo en relieve el incremento de lo que se ha denominado la feminización de la pobreza. La gran mayoría de ellas, previo al encierro, provienen de situaciones de pobreza, y de opresión de género y deben hacer frente a las consecuencias derivadas de ser mujer, ser pobre y ser gitana o extranjera (Molero, 2005).

4 http://www.institucionpenitenciaria.es/web/portal/documentos/estadisticas.html?r=m\&adm=TES\&am=2018\& $\mathrm{mm}=1 \& \mathrm{tm}=\mathrm{GENE} \& \mathrm{tm} 2=\mathrm{GENE}$ 
Respecto a la población extrajera que se encuentra en el Centro penitenciario de Algeciras, la nacionalidad más numerosa es la marroquí, debido a la cercanía de Marruecos con la ciudad de Algeciras y el delito cometido con más frecuencia contra la salud pública, siendo la mayoría de ellas detenidas en el puerto de Algeciras, procedentes de Marruecos. Otras nacionalidades de mujeres son de países como Cuba, Nigeria, Rumanía, Inglaterra, Francia o Bélgica. Para este grupo de mujeres el encierro se convierte en una situación aún más difícil que para otras reclusas, debido a la lejanía del entorno familiar y lo que esto significa: no reciben visitas, ni paquetes de ropa, ni apoyo económico y cuentan con menos posibilidades de alcanzar beneficios penitenciarios, como permisos de salida o la posibilidad de progresar de grado. A ello se suma el desconocimiento del idioma por parte de muchas de ellas, lo que dificulta su comunicación y les provoca una mayor desorientación en el medio penitenciario.

Muchas de las mujeres pertenecen a familias con dificultades sociales, con muy poca formación, con algunos casos de analfabetismo (especialmente en mujeres mayores) marroquíes y gitanas. Por otro lado también se encuentran mujeres jóvenes con formación media, que ante la falta de oportunidades y la tentación del «enriquecimiento fácil « que produce los delitos contra la salud pública (el tráfico de drogas) se lanzan sin pensar al delito. Encontramos también mujeres con toxicomanías en programas de desintoxicación de metadona o con tratamientos farmacológicos proporcionados por el centro para enfrentar la ansiedad y los problemas de sueños que padecen.

\section{Objetivos taller y metodología:}

Desde el comienzo en el año 2009, se ha llevado a cabo un total de siete talleres con una duración de diez a quince sesiones cada uno de tres horas. Cada taller ha sido único, dado que en cada uno han participado diferentes mujeres, y son ellas las que dotan de sentido y de carácter a la actividad, contando con unas 10 a 15 participantes.

El objetivo general del taller es utilizar la fotografía como herramienta de reflexión y expresión de su identidad individual y social, que mejore su autoconcepto y autoestima y que permita reducir los efectos de la prisionización.

Respecto a los objetivos específicos han ido variando en los diferentes talleres. A continuación se exponen los trabajados a los largo de estos años:

- Explorar su identidad a través de la imagen que refleje su mirada personal hacia ellas mismas.

- Potenciar la toma de decisiones, la autonomía y la responsabilidad.

- Desarrollar las capacidades creativas.

- Estimular los cinco sentidos en especial el sentido de la vista.

- Reforzar sus capacidades y descubrir nuevas habilidades personales y sociales.

- Favorecer el reconocimiento personal y social que mejore su autoestima.

- Crear un espacio de confianza y relajación.

- $\quad$ Fomentar trabajo de grupo y con ello las relaciones interpersonales, habilidades sociales y de comunicación. 
- Establecer nuevas vías de comunicación con su familia reforzando los vínculos familiares.

Trabajar a través de una metodología activa, flexible y participativa, basada en el proceso individual y de grupo, orientada a sus intereses y a la mejora de su realidad, favorecer el desarrollo de su capacidad de decidir de manera individual. A su vez les dota de responsabilidad y autonomía, y de manera grupal favorece sus habilidades sociales y comunicativas (González, Jiménez y Fandos, 2009).

Se trata de una metodología centrada en la persona, teniendo como principios la singularidad, autonomía y apertura:

- Singularidad: respetar el ritmo personal de cada persona, valorar sus capacidades y limitaciones y desarrollar la creatividad como vía de aprendizaje y mejora.

- Autonomía: basada en la libertad para poder elegir, decidir, aceptar y potenciar la toma de decisiones.

- Apertura: basada en la comunicación como herramienta socializadora. A través de la expresión artística descubrir nuevos modos de comunicación. El trabajo cooperativo articula el conocimiento y el desarrollo activo de las habilidades sociales.

La importancia de la creación de un espacio de confianza, fundamental en todo proceso arte terapéutico, es aún si cabe más en este contexto, donde la desconfianza, la envidia y el miedo afloran con gran facilidad. Para ello mi papel como arte terapeuta es fundamental al ser un referente externo a la institución, lo que permite que las personas se muestren de manera más sincera, actuando desde el acompañamiento y la facilitación del proceso, proporcionando los materiales y las técnicas. Intervenir desde la horizontalidad, tan necesaria en un espacio tan vertical, a través del diálogo y la escucha activa, favoreciendo la creación de un marco de trabajo favorable, seguro y continuo.

Bajo este escenario se realiza el aprendizaje básico de la cámara contando para la actividad con seis cámaras compactas digitales. Se trabaja de manera individual, en parejas o pequeños grupos para fomentar el trabajo grupal dependiendo del ejercicio planteado.

Se cuenta con un ordenador que al finalizar cada sesión se utiliza para descargar y visionar las fotografías realizadas. De esta forma se irá aprendiendo desde el punto de vista técnico a partir de sus propias imágenes. Asimismo nos sirve para reflexionar sobre el proceso, expresar cómo se han sentido, cómo se han visto, qué les ha gustado y qué no, creando un espacio de reflexión colectiva fundamental para valorar y reforzar los cambios que se van produciendo.

Un espacio abierto a sus propuestas e ideas como vía de desarrollo y fomento de la creatividad, trabajando la toma de decisiones como punto importante del taller, dado que estamos en un espacio donde tienen pocas ocasiones de tomar decisiones y expresar su opinión de manera libre. Cada participante decide qué quiere y no quiere encuadrar, cómo lo quiere ver, puede jugar con los planos (acercarnos y alejarnos) y situarse desde diferentes puntos de vista (arriba, abajo). Se plantean ejercicios abiertos a través de técnicas de retrato y autorretrato: cómo me veo, cómo me ven las demás, qué es lo que más me gusta de mí y lo que menos. Representarse mediante objetos especiales para ellas, partes de su cuerpo, aprender a observar la luz, trabajar con proyecciones de imágenes de espacios que desean mirar, sentir y que invitan a 
reflexionar sobre la mirada de cada una de ellas. El acto de mirar como un proceso de reflexión donde influye la cultura, la educación, los recuerdos, los gustos, los intereses, los sentimientos y las emociones. La mirada como conexión entre el mundo interior y exterior; siendo un fenómeno activo y cultural por el que construimos el mundo que nos rodea, y nos permite modificar nuestro yo interno. La mirada facilita el entendimiento y ello lleva inevitablemente al compromiso, esencia de la libertad (Merino,1999).

Se favorece así la creación de espacios de libertad como afirma (Landau, 2002) «El sistema abierto es el que posibilita la originalidad, la experimentación, la iniciativa y el descubrimiento...»(p. 110). La creatividad como vía de cambio, fomentando el pensamiento divergente que busca nuevas soluciones e ideas, que invita a pensar de manera flexible a los cambios e imprevistos, a reflexionar a través del arte, permitiendo trasladar estos procesos cognitivos y emocionales a su día a día.

\section{El proceso creativo a través de la fotografía}

El taller cuenta desde el principio con una gran aceptación por parte de las mujeres, despertando en ellas mucho interés al ser algo inaccesible en su día a día.

El primer día acuden expectantes, con mucha curiosidad e interés, muchas mujeres a los largo de estos años al llegar preguntaban: "¿qué vamos a fotografiar aquí?...si no podemos salir». Ante esta cuestión en el primer taller, y que se repetirá en otras ocasiones al comienzo, surge el nombre del taller «Mirada Interior", aprender a mirar hacia una misma, hacia el otro, a expresar, a explorar, apreciar lo que son y vivir de manera diferente a darse cuenta de los cambios y a reflejarse como un espejo donde verse y reconocerse. Como afirma (López, 2006) «La práctica fotográfica genera reflexión sobre la mirada hacia el mundo y hacia nosotros mismos» (p. 139). La imagen como medio de auto aceptación, explorando a través de la mirada, dando más importancia a ésta que al proceso técnico. Aprender a mirar con atención, descubrir nuevas formas de mirar, mirarse y ser miradas, desde nuevas perspectivas, sentirse protagonistas ante la cámara, posar, transformarse, jugar a ser y estar, desconectar de la realidad exterior para adentrase en su interior.

Desde la primera sesión se van creando las bases para la creación de un espacio de confianza y de transformación, mediante la estructura del encuadre del mismo: los objetivos del taller, el horario de las sesiones, el espacio de trabajo, las normas establecidas de manera democrática. Se crea un mural con ellas y se coloca en un sitio visible del espacio, esto sirve para poder acudir a los acuerdos establecidos entre el grupo en momentos que surgen diferencias entre las participantes, favoreciendo así el dialogo como vía de resolución de conflictos.

En las primeras sesiones comenzamos a reflexionar y trabajar sobre la identidad, mediante el retrato y el autorretrato, descubriendo nuevas formas de mostrarse a través de partes de su cuerpo, sus ropas, sus tatuajes, sus objetos, las sombras, aprendiendo a utilizar la imagen de una manera más simbólica diferente a lo que están acostumbradas. Apreciar la diferencia entre ver y mirar, reflexionar sobre el cómo miro, y aprender a mirar a través de una cámara mediante el conocimiento básico de la herramienta y el lenguaje visual para facilitar y mejorar su expresión. Antes de comenzar a fotografiar se les pide que reflexionen sobre cómo quieren ser fotogra- 
fiadas, dónde y cómo, preparar el espacio, pararse a pensar, elegir y decidir sobre lo que quieren.

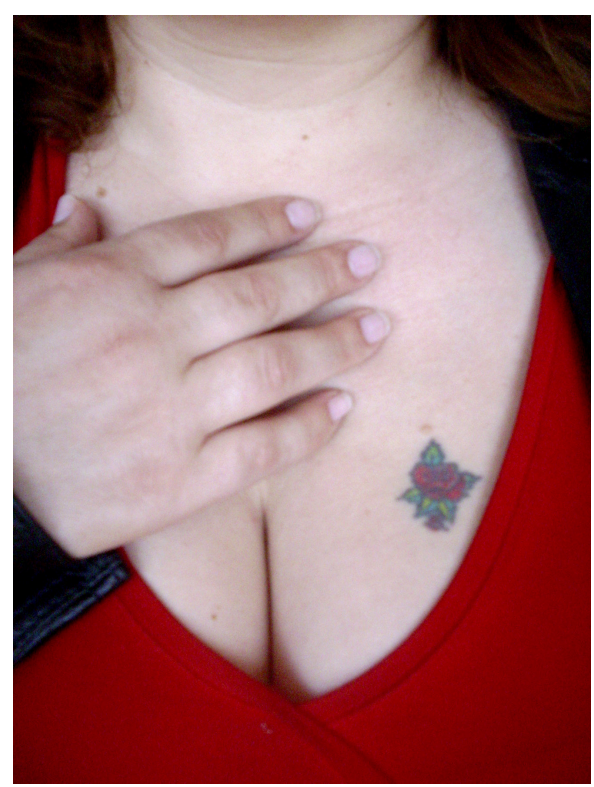

Foto 1. Autoretrato.

Foto 2. Autoretrato.

Fotografías realizadas por mujeres participantes en el taller.

Sobre todo en las primeras sesiones esta dinámica de reflexión sobre la mirada se realiza antes de darles la cámara, ya que una vez repartidas es tal el entusiasmo que se olvidan de todo y no se paran a mirar, ni a pensar. Sin embargo en sesiones posteriores, cuando la mirada comienza a ser más reflexiva, se facilitan muchos momentos de vivir ese entusiasmo de fotografiar y posar, de mirar y ser miradas, momentos de exaltación convirtiendo el proceso de la toma fotográfica en acontecimiento en sí mismo (Sontag, 2005). Hacer fotos implica acción mental, corporal y emocional. Sentir la fotografía como acto (Tisseron, 2000), sin importar el resultado y disfrutar el visionado posterior que facilita el recuerdo de esos momentos de distensión y de encuentro. Reforzando el sentimiento de grupo y favoreciendo el establecimiento de relaciones interpersonales más positivas.

La confrontación con su propia imagen en un primer momento genera conflicto en muchas de las mujeres, no les gusta verse e incluso se sorprenden ante su imagen, la autoimagen de ellas dependerá del grado de prisionización en el que se encuentren. Factores como el tiempo de condena: a mayor tiempo peor imagen. El grado de autoestima que poseen, la autoconfianza y la aceptación de su situación. A esto hay que añadir que en los centros por seguridad no existen espejos de cristal, los que hay son de un material de plástico que no reflejan una buena imagen, si a esta imagen distorsionada que les devuelve «el espejo taleguero» (argot carcelario), se añade su imagen mental gravemente dañada tras el encierro, nos encontramos con mujeres que tienen una imagen muy negativa de ellas mismas. La imagen mental se transfiere a la física, como decía una de las participantes: «desde que estoy en la cárcel me veo muy mal tanto por fuera como por dentro». Poco a poco esta percepción se va transformando, la fotografía les va devolviendo otra imagen. 
Muchas de ellas comienzan a arreglarse más, a cuidarse más, a mejorar su imagen exterior, lo que beneficia su imagen interior y les va permitiendo verse y reconciliarse con su propia imagen traduciéndose en una reconciliación personal, tanto a nivel físico como psicológico.

Según vamos avanzando en el taller se va trabajando de una manera más profunda las emociones, los sentimientos, los deseos y los sueños, comenzando a conectar con su interior, aflorando temas como su vida en la prisión, la familia, la sociedad...su visión interior y exterior de la vida. Comienzan a aprender a expresar cómo se sienten y a expresarlo a través de la imagen, utilizando técnicas variadas como la escritura creativa, la creación de murales con pinturas que luego utilizan para fotografiarse sobre él, la pintura sobre el cuerpo con palabras relacionados con vivencias y esperanzas, o la escritura en papeles a modo de foto encuesta.
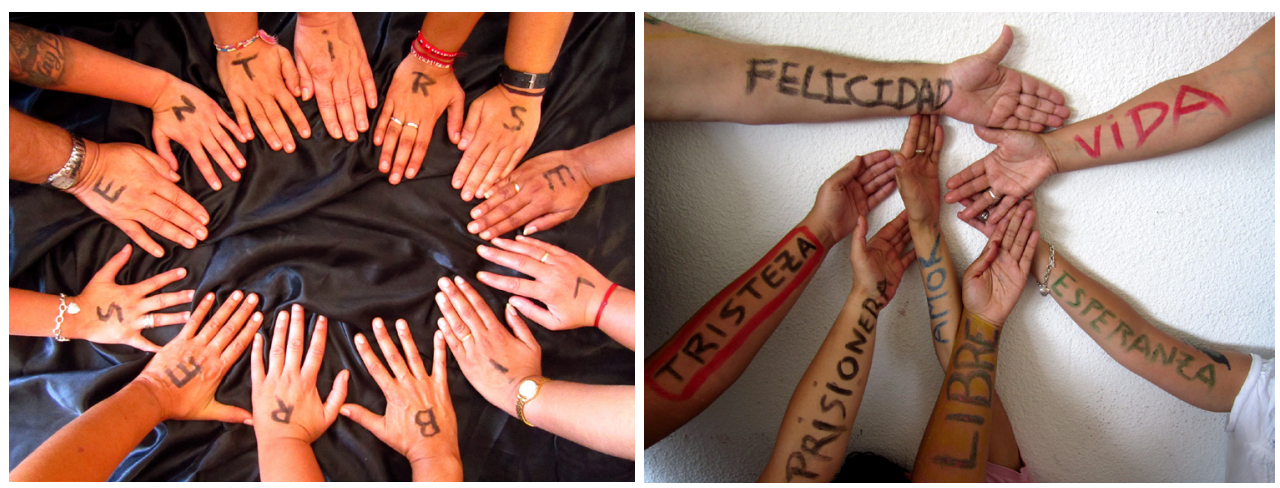

Foto 3. Sentirse libre. Foto 4:. Sentimientos.

Fotografías realizadas por mujeres participantes en el taller.

Desde el comienzo se va trabajando el concepto de transformar el espacio, observando la luz, llenando de color las paredes, a través de telas y pinturas que se crean de manera colectiva. Las mujeres también traen objetos personales, vestidos o ropa para cambiarse, y se llevan diferentes elementos para ayudar a crear otro espacio como globos, pañuelos, telas y papeles de colores etc...La norma de seguridad por parte del Centro de no poder fotografiar nada del espacio que no sea el aula, pronto se convierte en algo que no necesitan, no desean mirar tras las rejas del aula, ni en los pasillos que les recuerda el lugar donde están, desean mirar hacia a ellas mismas, aumentando su deseo de transformar el espacio y transformarse con él.

El trabajo con las proyecciones se realiza en las últimas sesiones para reflexionar sobre el espacio interior, el poder de la mente para sentirse libre, Como afirma Laing (1987) «la importancia de trabajar mediante la mente de los presos que en todos los casos continua libre» (p. 220) y el arte les permite liberar sus emociones. Mediante proyecciones de espacios exteriores, se fotografían y reflexionan sobre la libertad interior y la importancia de la actitud para promover el cambio. 

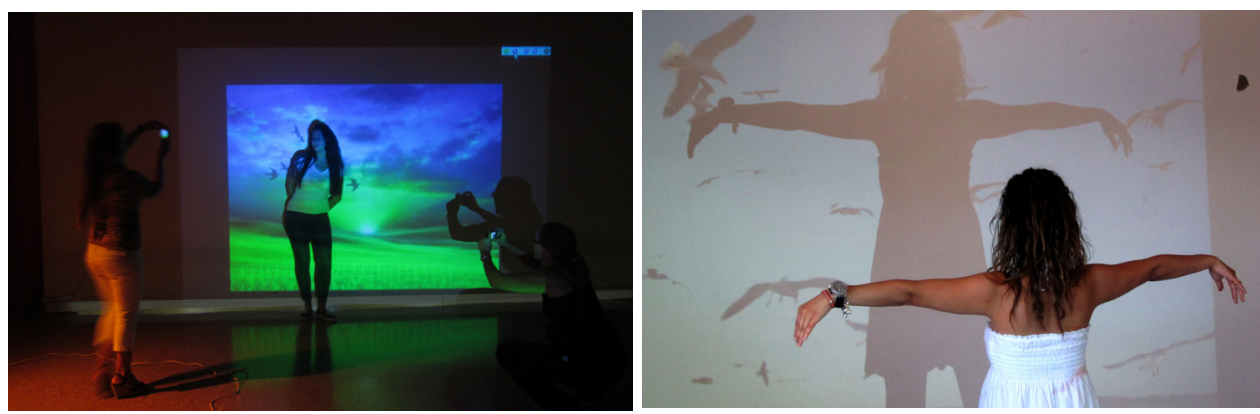

Foto 5. Proyecciones Foto 6: Mirada interior.

Fotografías realizadas por mujeres participantes en el taller.

En estas sesiones las mujeres se muestran con mayor seguridad y confianza, ellas eligen sus espacios: éstos pueden ser lugares conocidos como su ciudad, elementos culturales como la luna árabe, y la naturaleza, que tanto echan de menos: el mar, la montaña, las flores etc... y comienzan a reflexionar sobre su identidad cultural. Este proceso nos lleva unas dos o tres sesiones y siempre ha sido un momento mágico del taller. Las mujeres eligen su espacio, se acompaña de música, algunas bailan, se desplazan con su cuerpo por el espacio y con su mente viajan a otros lugares. El contacto con la luz y la música estimula sus sentidos proporcionado un bienestar interior. Es en estas sesiones cuando aflora con mayor fuerza la cohesión grupal que se ha ido creando a lo largo del taller. La persona que elige el paisaje proyectado posa, actúa, se muestra ante el grupo que realiza las fotos, esto les permite disfrutar de un momento de protagonismo, aspecto muy importante para reforzar la autoestima, en mujeres que en muchas ocasiones arrastran una trayectoria vital de marginación, episodios de violencia y de rechazo social, donde la mirada sobre ellas apenas ha existido de una manera positiva. Comienzan a transformar su mirada y todos los beneficios que este proceso produce en su interior, el rechazo a su imagen en las primeras sesiones se remplaza por el entusiasmo de encontrase con una imagen que les agrada más de sí mismas.

Cada sesión es un aprendizaje, se crean momentos de distensión y relajación, permitiendo soltar las tensiones acumuladas en su día a día, olvidando el espacio que les aprisiona y descubriendo nuevos espacios interiores que les libera, como algunas mujeres expresan « aire para respirar», este aire les permite descansar y afrontar su realidad con otra actitud.

Al finalizar se eligen las imágenes que ellas quieren y se crean collages en formato postal y tarjetas para enviar a sus familiares, reduciendo así la ansiedad que produce la separación en ambos lados de los muros. Por un lado la mujer siente que ha abandonado a sus hijos/as surgiendo en ellas un sentimiento de culpabilidad, este sentimiento de abandono es reciproco por parte de los hijos e hijas, que dependiendo de su edad entienden mejor o peor la reclusión de sus madres. Sentimiento que unido a la visión estigmatizada de la cárcel y de las personas que allí habitan, produce en las familias una gran preocupación. La fotografía permite hacer presente las ausencias, acercar y reconfortar a las familias al recibir una imagen donde ven a sus madres, hijas, hermanas, tranquilas, bellas y fuertes, caminando con dignidad a pesar de las adversidades. 
En las primeras ediciones del taller en el año 2010 se realizó una exposición en la calle con motivo del festival «Encuentro de cultura y cooperación creativa EC $\cdot 3$ »que se celebró en Algeciras, donde se invitó a exponer el trabajo realizado en dos talleres de fotografía bajo el título de "Mirada Interior». Para la inauguración salieron un grupo de mujeres reclusas, que se encontraban próximas de alcanzar el tercer grado penitenciario. La experiencia fue muy enriquecedora para todos y todas las participantes, creando bastante expectación entre las personas asistentes al evento al saber que iban a acudir un grupo de mujeres presas, reflejando la estigmatización de este colectivo y rompiendo muchas etiquetas de la imagen negativa que se tiene de ellas. La fotografía por tanto se convierte en una herramienta eficaz para sensibilizar y acercar realidades desconocidas y rechazadas.

\section{Posibilidades de la fotografía como herramienta terapéutica y educativa en el ámbito penitenciario}

La utilización de la fotografía en este ámbito es algo innovador y cobra aún más protagonismo, al ser un elemento inaccesible para las personas privadas de libertad, Dentro de las prisiones, por razones de seguridad, no está permitido el uso de ningún instrumento de grabación de imagen y voz por parte de los/as internos/as. Este factor, unido al carácter lúdico que caracteriza a la actividad artística, despierta mucho interés y la motivación para participar. Definiendo lo lúdico, como una área de experimentación, de sentirse libre, la libertad de dudar, de buscar y aprender (López, 2006).

Una de las condiciones fundamentales para que se produzca la reinserción es que la persona acepte su situación, la fotografía permite reflexionar y comenzar aceptar el tiempo presente que viven y proyectarse hacia el futuro de una manera más integrada (Moreno,2016). El trabajo con la imagen fomenta la toma de decisiones que produce un efecto positivo en la autoestima como afirma López (2006)»El aprendizaje de la fotografía tiene un efecto positivo en la autoestima, desde la capacidad de tener el control de la imagen a través de la cámara, a controlar los distintos procesos y hacerse responsable de ellos» (p. 142). Esta responsabilidad promueve la autonomía de las personas mediante la puesta en práctica de la decisión, la opinión y el trabajo en equipo, consiguiendo que el aprendizaje social se produzca de una manera más efectiva.

Un lenguaje que les permite expresarse libremente, una metodología basada en el trabajo individual y de grupo, fomentando la participación activa de las mujeres, orientada a sus intereses y a la mejora de su realidad, con beneficios tan positivos como el desarrollo de su capacidad de decisión, aumentar su responsabilidad y autonomía. Todo ello facilita el reconocimiento personal al convertirse en protagonistas de sus propios cambios, facilitando procesos de empoderamiento que se producen a través de la experiencia, ganando autoconfianza y fuerza para realizar cambios en su vida, siendo más autónomas y libres (Carballo, 2016).

La fotografía como afirma (Klein, 2006) «juega con el espacio y el tiempo» (p. 26) en un ámbito donde estos dos elementos tienen un gran peso sobre las personas. El trabajo con la imagen les permite crear un nuevo espacio que les relaja de las tensiones diarias y captar un tiempo que aunque la mayoría quieren olvidar, les recuerda que a pesar de todo están vivas. A su vez les hace llenarse de ilusión 
ante el tiempo presente, y transformar el sentimiento de tiempo vacío y perdido que poseen, en un tiempo útil, de ilusión, de encuentro y de aprendizaje. Esto posibilita a la vez mejorar su percepción del futuro, observando cómo durante la actividad va mejorando su auto concepto y con ello la autoestima, cambios que se producen y observan en cómo van aceptando y encontrándose al verse reflejadas en la imagen fotográfica.

La fotografía permite crear y mejorar las relaciones; mejorando la comunicación a través del acto fotográfico se fomenta otro tipo de interacción más positivo. Algunas mujeres apenas hablan en el módulo por diferencias culturales o por miedos y en la actividad se conocen, se acercan, se fotografían entre ellas, y reactivan sus relaciones en su día a día. En todas las ocasiones ha sido un encuentro multicultural, facilitando la interculturalidad, mediante el encuentro de las diferentes culturas, rompiendo los guetos que se generan dentro de los modelos residenciales, donde las mujeres sólo se relacionan con mujeres de su misma nacionalidad y cultura, siendo esto más representativo con el grupo de mujeres marroquíes y mujeres gitanas. También se renueva la convivencia que en muchas ocasiones es un punto de conflicto importante dentro de las prisiones.

El taller de fotografía les ayuda a romper con su rutina y les permite conectar con ellas mismas de una manera positiva y con su familia al tener la oportunidad de enviar las imágenes a sus seres queridos. Así acercan de una manera simbólica dos mundos separados por muros y desconocimiento, lo que repercute positivamente en el mantenimiento y refuerzo del vínculo familiar, disminuyendo los efectos que produce la separación forzosa en especial con sus hijos/as.

\section{Conclusiones}

La intervención social a través del arte permite disminuir los efectos de la prisionización, tanto a nivel físico mediante el uso de las diferentes materiales que estimulan los cinco sentidos afectados tras el encierro, como a nivel psicosocial disminuyendo la desconfianza, el miedo y la ansiedad que les bloquea y les hace adoptar actitudes negativas. Permite la expresión libre, alejándose del discurso aprendido al que están acostumbradas, poniendo en práctica una nueva vía de conocimiento y comunicación que mejora sus relaciones intra e interpersonales.

La importancia de adoptar una perspectiva de género en la intervención con mujeres reclusas, donde se considera clave el desarrollo de estrategias de empoderamiento a partir del desarrollo de la autoestima, el autoconocimiento, las habilidades sociales, que promuevan el desarrollo de la igualdad entre hombres y mujeres. El arte fomenta estos aprendizajes fundamentales para el crecimiento personal y social como afirma Pozo (2016) basándose en las investigaciones de Añaños y Del Pozo (2012) «Los programas culturales y artísticos suponen una de las mayores prácticas de libertad y recuperación en el ámbito penitenciario» (p. 114).

Con este artículo se pretende contribuir a visibilizar el poder del arte como herramienta de transformación social dentro del ámbito penitenciario con el trabajo realizado con el colectivo de mujeres reclusas. El proceso creativo a través de la imagen, permite elaborar desde otra perspectiva los conflictos internos que produce la falta de libertad, promueve la reflexión y la comunicación con una misma y con el grupo, motiva a la participación y genera sensaciones de placer, disfrute y felicidad, 
espacios de encuentro y confianza, necesarios para retomar el día a día con mayor serenidad. Son muchos los momentos mágicos creados dentro de cada taller con el grupo, reflejo de estos momentos queda en las imágenes que evocan los recuerdos y las palabras que surgen en el espacio y tiempo penitenciario como «paz», «felicidad», «aprendizaje», «mejorar», «sentir», «emocionarme», «alegría», «tranquilidad», «compañerismo», «ilusión». Emociones, sentimientos, acciones y valores que dentro del contexto de encierro cobran aún mayor relevancia.

\section{Referencias bibliográficas}

Arnoso Martínez, A. (2005). Cárcel y trayectorias psicosociales: actores y representaciones sociales. San Sebastián: Alberdania.

Añaños Bedriñana, FT. (2010). Las mujeres en las prisiones: la educación social en contextos de riesgo y conflicto. Gedisa: Barcelona.

Segovia Bernabé, J.L. Consecuencias de la prisionización. Recuperado de http://www. derechopenitenciario.com/comun/fichero.asp?id=1003

García-Bores Espí, JM. (2003). El impacto carcelario. Universidad de Barcelona. Recuperado de http://www.monografias.com/trabajos106/impacto-carcelario-dr-josep-garcia-boresespi/impacto-carcelario-dr-josep-garcia-bores-espi.shtml.

Goffman, E. (1972). Internados. Buenos Aires: Amotrortu Editores.

González Soto, A, Jiménez Gonzalez, JM y Fandos Garrido, M.(2009). Procesos y propuestas de enseñanza y aprendizaje: el sistema métodológico, En Medina Rivilla, A y Dominguez Garrido, M. (edit). Didáctica. Formación básica para profesionales de la educación (pp.281-320). Madrid: Editorial universitas y UNED.

Herrera Enríquez, C y Expósito Jiménez, F. (2010). Una Vida entre Rejas: Aspectos Psicosociales de la Encarcelación y Diferencias de Género. En Psychosocial Intervention, vol.19, núm. 3, 235-241. Recuperado de: http://www.redalyc.org/pdf/1798/179817507004.pdf

Klein, J.P. (2006). Arte terapia, una introducción. Barcelona: Octaedro.

Landau, E. (1987). El vivir creativo: Teoría y práctica de la creatividad. Barcelona: Herder.

Lang, J (1987), La terapia artística en las cárceles, Cap 10, pp.215-235. En Dalley, T. El arte como terapia. Barcelona: Herder.

Martinez Díaz, N; López Fernandez Cao, M.(2006).Arteterapia. Conocimiento interior a través de la expresión artística. Madrid: Tutor.

Merino, JL. (1999).El Acto de mirar. En revista imagen óptica, Vol. 1, Oct-Dic 1999. Recuperado de http:/www.merinopticoservicios.com/articulo3.html

Molero Naredo, M. (2005) ¿Qué nos enseñan las reclusas? La criminalización de

la pobreza desde la situación de reclusas extranjeras y gitanas. Recuperado de

https://buleria.unileon.es/bitstream/handle/10612/1447/NaredoMolero.pdf?sequence=1

Moreno, A.(2016). La mediación artística arte para la transformación social. la inclusión social y el desarrollo comunitario. Barcelona: Octaedro.

Pozo Serrano, F (2016). El enfoque diferencial de género en las intervenciones socioeducativas en ámbitos penitenciarios, pp.110-120. En Revista de Educación Social (RES) Educación Social en Centro penitenciarios, $\mathrm{N}^{\mathrm{o}}$ 22, Recuperado de http://www.eduso.net/res/ revista/22

Sontag, S. (2006). Sobre la fotografía. Madrid: Alfaguara.

Tisseron,S .(2000).El misterio de la cámara lucida, fotografía e inconsciente. Salamanca: Universidad de Salamanca. 
Yagüe Olmos, C.(2007) Mujeres en prisión. Intervención basada en sus características, necesidades y demandas. En Revista Española de Investigación Criminológica (REIC), $\mathrm{n}^{\mathrm{o}}$ 5, 1-4. Recuperado https://dialnet.unirioja.es/servlet/articulo?codigo $=2477673$

II Encuentro de Cultura y Cooperación Creativa EC 3 http://www.fmyv.es/leer-mas. php?idNoticia $=99$

Valverde. (1997). La cárcel y sus consecuencias: la intervención sobre la conducta desadaptada .Madrid: Popular. 